\title{
Hand injuries in south Wales coal miners
}

\author{
WJ MORGAN AND SN HARROP
}

From the Accident and Emergency Department, Royal Gwent Hospital, Newport, Gwent NPT 2UB

ABSTRACT Fifty eight coal miners attended the Royal Gwent Accident and Emergency Department with serious hand injuries over a three year period. The commonest cause of the injuries was falling rock or coal from the pit roof crushing the hand and the commonest type of injury was the crushed, compound fracture of the terminal phalangeal area of the digit, with or without pulp loss. Records of the time off work with the injury were obtained in 52 miners. Only seven (13\%) returned to work within one month. Of 40 individual distal phalangeal injuries reviewed after one year, only four $(10 \%)$ had normal sensation and full movement at the distal joint. Nevertheless, only seven miners $(13 \%)$ had to alter their initial occupation at the mine and move to lighter duties.

Five major coal mines in south Wales (Blaen Serchan, North Celynen, South Celynen, Markham, and Oakdale) usually send their accident victims to the Royal Gwent Hospital. The hospital is at the south end of one of the Welsh valleys and, as is usual in south Wales, the coal mines are at the north end. Accident victims therefore usually travel between 10 and 20 miles down the valley for treatment. In recent years major coal mining accidents are rare and are usually widely reported. ${ }^{1}$ This perhaps gives the general public the impression that with modern coal mining methods the risk has disappeared from coal mining. Certainly the danger to the miner's life is greatly reduced with the use of modern coal cutting equipment and, more importantly, scientifically designed hydraulic pit props to support the roof. It is our impression, however, that the coal mining process can still result in serious accidents, particularly to the hands of miners working at the coal face. Often the accidents result from handling or assembling the equipment that makes mining much safer, and it is the purpose of this survey to study a series of hand injuries with particular regard to the mechanism of injury and the type of injuries sustained.

\section{Patients and methods}

A prospective study was carried out on coal miners who attended the accident unit of the Royal Gwent Hospital with serious hand injuries between November 1980 and November 1983. A total of 58 patients was seen in this period. A serious hand injury was defined as one in which there was either damage

Received 11 March 1985

Accepted 25 March 1985 to bone, tendon, or nervous tissue, or the skin and soft tissue damage alone was considered serious enough to lead to possible complications. An attempt was made to review all cases for at least one year after $\stackrel{\mathbb{\phi}}{\varnothing}$ the accident. Forty one cases were reviewed in such a manner, 17 cases being lost to follow up.

A record was kept of the exact mechanism of injury, the nature and site of the injury for eac individual digit damaged, and the initial an or subsequent treatment carried out.

In 52 cases the total time off work with the injug was noted, whether the patient had to alter his type of work, and whether more than one period off work was necessary. Patients seen after one year with distal $\stackrel{\varnothing}{\varnothing}$ phalangeal injuries were asked whether they $\underset{\vec{F}}{\overrightarrow{2}}$ considered sensation at the digital tip to be normal, $\frac{0}{3}$ painful, or to have decreased, these parameters being considered most relevant to heavy manual workers. In those complaining of decreased sensation static two point discimination was tested using a bent paper $\mathbb{D}$ clip. In phalangeal injuries seen after one year movement of each digit was tested and recorded as either being short of the palm, just reaching the palm, or flexing to the distal crease of the palm.

\section{Results}

The mechanism of injury, the type of injury for each individual digit, and the initial treatment carried out $N$ are shown in tables 1-3. Conservative treatment consisted of surgical toilet, closed or open fracture $\mathcal{O}$ reduction without internal fixation, skin suture, $\mathbb{\omega}$ application of simple dressings to finger tips, and drainage of infection.

Often a relatively minor soft tissue injury in one $\bar{\varnothing}$ digit accompanied a more serious injury in another? 
Table 1 Mechanism of coal miners' hand injuries

\begin{tabular}{lr}
\hline Falling rock, coal & 20 \\
Moving cable, belt, chain & 15 \\
Other falling or moving mining implements & 15 \\
Boring machine & 2 \\
Non-specific mining & 6 \\
Total & 58 \\
\hline
\end{tabular}

Table 2 Classification of individual digital injuries

\begin{tabular}{lr}
\hline Compound fracture distal phalanx & 13 \\
Partial amputation pulp distal phalanx & 12 \\
Loss of pulp distal phalanx & 10 \\
Complete amputation through digit & 10 \\
Soft tissue only & 17 \\
Fracture proximal and middle phalanges & 5 \\
Serious joint disruption & 2 \\
Infected soft tissue injury & 2 \\
Mallet finger & 1 \\
Total & 72 \\
\hline
\end{tabular}

Table 3 Primary treatment of individual hand injuries

\begin{tabular}{lr}
\hline Conservative & 55 \\
Advancement flap & 5 \\
Skin graft: & 3 \\
Distal flap & 2 \\
Terminalisation & 9 \\
Internal fixation & 2 \\
Digital nerve repair & 1 \\
\hline
\end{tabular}

and these have been classified accordingly.

In 53 cases the digits only were affected, in 36 cases a single digit, in 15 cases two digits, and in two cases three digits. Table 4 shows the site of the individual digital injuries. The other injuries consisted of two metacarpal fractures, one digital nerve injury in the palm, and two soft tissue injuries of the dorsum of the hand.

Seven patients were off work less than one month, 29 between one and three months, nine between three and six months, and seven between six months and one year. Three patients were lost to follow up before they were officially discharged back to work and in two cases the miners' strike interfered with the assessment of the total time off work. One patient took early retirement. Seven patients had more than one period off work and seven patients moved to a lighter job, usually on the surface. Thirty nine patients were face workers involved in the coal cutting process.

Forty individual distal phalangeal injuries were seen after one year from the accident. Fifteen had normal sensation, seven complained of pain in the

Table 4 Site of digital injuries

\begin{tabular}{lcc}
\hline & Dominant hand & $\begin{array}{l}\text { Non-dominant } \\
\text { hand }\end{array}$ \\
\hline Thumb & 3 & 3 \\
Index & 6 & 9 \\
Middle & 11 & 7 \\
Ring & 10 & 10 \\
Little & 7 & 6 \\
Total & 37 & 35 \\
\hline
\end{tabular}

end of the finger, and 18 of decreased sensation. In the latter group nine patients had a two point discrimination greater than $1 \mathrm{~cm}$. Forty two individual phalangeal injuries were seen one year after the accident. In ten cases flexion of the finger was short of the palm, seven just reached the palm, and 25 were able to flex to the distal crease.

Combining sensation and range of movement in distal phalangeal injuries seen one year after the accident, only four patients had normal sensation and flexion to the distal palmar crease.

A second surgical procedure was required in six cases, three of these being for an initial terminalisation.

\section{Discussion}

In the early mining days major life threatening accidents were due to large falls of coal or rock from the pit roof, crushing or trapping the coal miners. It is interesting that in our survey the commonest cause of hand injuries is, again, from smaller falls of rock or coal from the pit roof. This is particularly likely to occur when a large amount of rock or stone is found in the coal seam; the seam is then of poor quality and the usual smooth action of the modern coal cutter is interrupted.

The injuries reported in our survey resulted in a considerable time off work, and it is generally recognised that hand injuries in manual workers result in more time off work than other members of the working population. ${ }^{2}$ It is our opinion that there can be no heavier manual work than that of a coal mining face worker and therefore long periods off work may be expected, even from relatively simple crush injuries of the finger tips.

The types of injury seen are entirely consistent with the mechanism of injury. Falling rock or coal, causing the typical bursting, blackened compound fracture of the terminal phalangeal area of the fingers, which are also easily cut or amputated by the moving belts and chains essential for modern coal mining (fig). These types of injury are well recognised as a source of residual disability in the hand. ${ }^{3}$

These is little difference in our survey between the dominant and non-dominant hand regarding the site of injuries, although one would expect the dominant hand usually to be affected in accidents with moving machinery. ${ }^{4}$

We are unable to suggest how to reduce the incidence of these injuries. General safety standards are high and most of these injuries occur during the normal coal cutting process associated with the handling of equipment essential for the mining process. It appears, therefore, that while coal is going to be mined up to half a mile underground injuries 


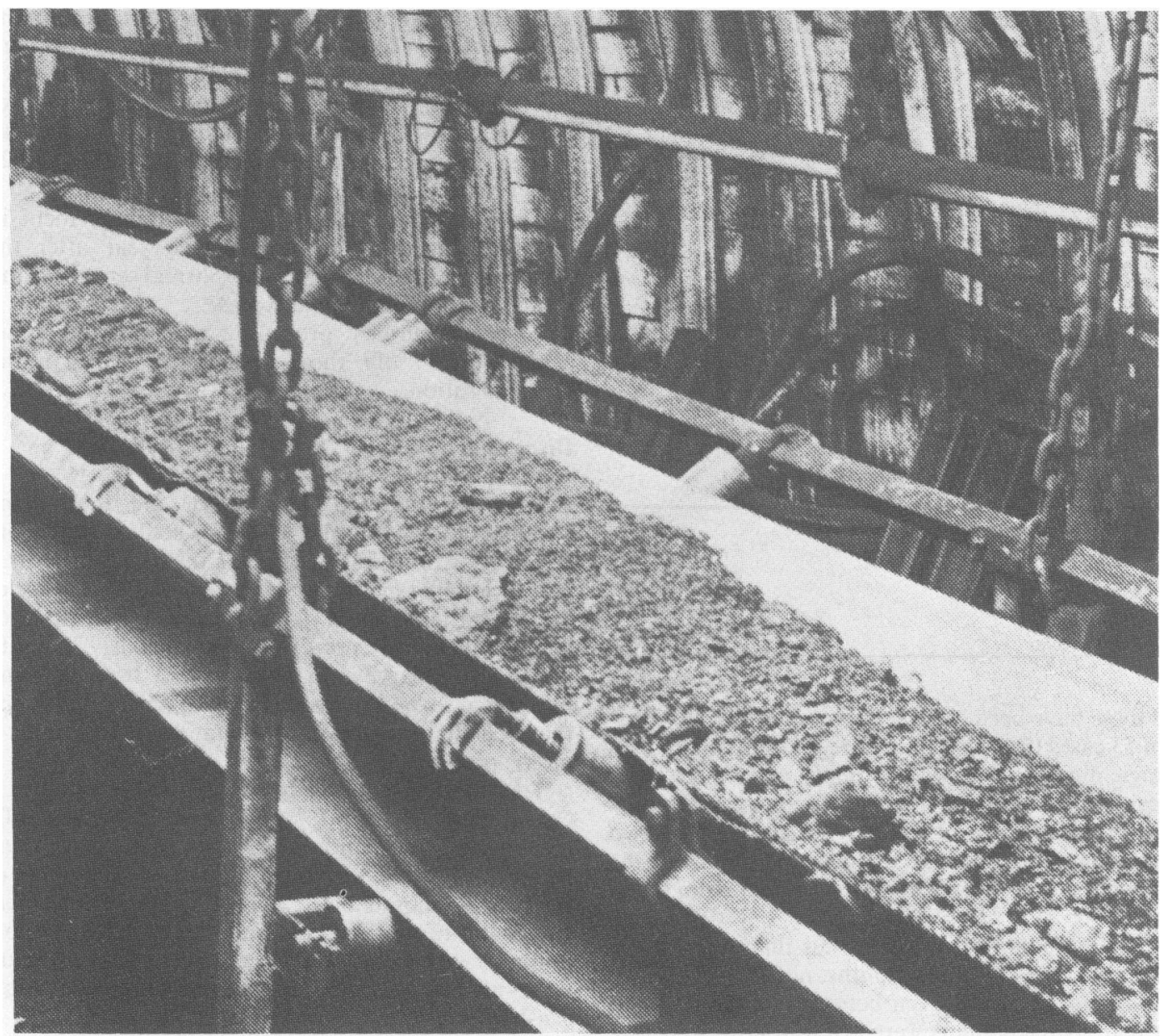

Typical underground conveyor belt system. Finger tips may easily be caught between rollers and belt.

such as these will have to be accepted as the price the miner pays for bringing the coal to the surface. Other underground mining processes are also associated with a significant number of hand injuries. ${ }^{5}$

It can be seen that many of these injuries were managed conservatively. The typical bursting finger tip injury, contaminated with coal dust, is not usually suitable for complicated surgical procedures and we would agree that in industrial hand injuries many of the operations on the distal part of the finger are unnecessary ${ }^{3}$ and often the most conservative initial care is indicated. ${ }^{6}$

In our survey most patients with finger tip injuries did not have a return of normal sensation. This is not surprising, considering the mechanism of injury and there is no real reason why a badly crushed finger should have normal sensory return. As most of our patients eventually returned to face working, this is not necessarily a problem with a heavy manual $\stackrel{\square}{\exists}$ worker. It is far more important when treating this type of patient to assess results according to the practical functioning of the hand, as often clinical of methods of sensory testing do not relate accurately to the patient's ability to use the hand usefully. ${ }^{7}$

Six of the patients required a second surgical procedure, three of the cases being an initial terminalisation. It cannot be emphasised too strongly that amputations to preserve length in the fingers are 0 useless in heavy manual workers. The patient will $\tilde{O}$ simply end up with a painful finger that he will not use. It is our opinion that, as used to be taught for leg 0 amputations, one cannot leave too much skin covering the end of a terminalised finger that will be used for manual work. 
We acknowledge the help of Mrs $\mathrm{K}$ Bolt with the preparing and typing of this paper and also the National Coal Board in Wales for permission to use the illustration in the text.

\section{References}

${ }^{1}$ Alister C, Hamilton GM. The Cardowan coal mine explosion: an experience of a mass burns incident. Br Med J 1983;287:403-5.

${ }^{2}$ Johns AM. Time off work after hand injury. Injury 1981;12:417-24.

${ }^{3}$ Conolly WB, Goulston E. Residual disability after industrial hand injuries. Med J Aust 1976;2:895-6.

${ }^{4}$ Walpole B. Industrial hand injury. Aust Fam Physician 1977;6:1089-92.

${ }^{5}$ Scott QJ. Hand injuries at a mine hospital. Cent Afr $J$ Med 1978;24:61-4.

${ }^{6}$ Sandzen SC, Jr. Crush injuries of the hand. Med Trial Tech $Q$ 1972;19:282-9.

${ }^{7}$ Moberg E. Criticism and study of methods for examining sensibility in the hand. Neurology 1962;12:8-19.

\section{Correction}

Mesothelioma and asbestos fibre type

In the second paragraph of this letter (August, $p$ 567) it should have read "... small quantities of amphibole fibre at the former, we would not agree with him." 